\title{
Isolation of chromosome-21-specific DNA probes and their use in the analysis of nondisjunction in Down syndrome
}

\author{
J. Galt ${ }^{1^{*}}$, E. Boyd ${ }^{1}$, J.M.Connor ${ }^{1}$, and M.A.Ferguson-Smith ${ }^{2}$ \\ ${ }^{1}$ Duncan Guthrie Institute of Medical Genetics, University of Glasgow, Yorkhill Hospital, Glasgow G3 8SJ, UK \\ ${ }^{2}$ Pathology Department, University of Cambridge, Tennis Court Road, Cambridge CB2 1QP, UK
}

Summary. Thirteen single-copy, chromosome-21-specific DNA probes were isolated from a recombinant library made from flow-sorted chromosome 21 DNA and regionally mapped using a panel of somatic cell hybrids. Five probes mapped in the $21 \mathrm{q} 21-\mathrm{q} 22.1$ region, six to the $21 \mathrm{q} 22.1$-qter region, and one to each of the regions $21 \mathrm{q} 22.1-\mathrm{q} 22.2$ and $21 \mathrm{q} 22.3$. Two of these probes, one of which maps in the critical region for Down syndrome, have recently been shown to be expressed at high levels in Down syndrome brain tissue (Stefani et al. 1988). Following preliminary screening for restriction fragment length polymorphisms (RFLPs), five polymorphisms were discovered with four of the chromosome 21 DNA probes. A frequent $M s p$ I polymorphism detected by one of the probes was used in conjunction with four previously described polymorphic chromosome 21 probes to analyse the origin of nondisjunction in 33 families with a child or fetus with trisomy 21. The parental origin of the additional chromosome 21 was determined in 12 cases: in $9(75 \%)$ of these it was derived from the mother and in the other 3 cases $(25 \%)$ it was of paternal origin. Cytogenetic analysis of Q-banding heteromorphisms was informative in three of five families tested, and in each case the RFLP results were confirmed. The meiotic stage of nondisjunction was defined with confidence in five families, the results being obtained with pericentromeric RFLP or cytogenetic markers. Recombination between two nondisjoined chromosomes was demonstrated in one family and is consistent with the view that a lack of recombination between chromosome 21 homologues or failure of their conjunction is not the invariable cause of trisomy 21.

\section{Introduction}

Down syndrome is caused by the presence in an individual of three copies of gene loci in the critical 21 q 22 region of chromosome 21 (Summitt 1981) and is usually taken to be due to meiotic nondisjunction (or anaphase lag) leading to trisomy 21. Cytogenetic studies of heteromorphisms associated with the short arm of chromosome 21 have shown that in $80 \%$ of cases the additional chromosome in trisomy 21 is maternal in origin (reviewed by Juberg and Mowrey 1983). The usefulness of cytogenetic heteromorphisms in the analysis of chromo-

\footnotetext{
* Present address and address for offprint requests: Howard Hughes Medical Institute, University of Michigan, Medical School, Room 3520, MSRB I, 1150 West Medical Center Drive, Ann Arbor, MI 48109 , USA
}

somal nondisjunction is limited, however, by three technical problems. First, in most cases, results are based on the subjective evaluation of chromosomal heteromorphisms and thus even if the scoring is performed by independent observers, it is possible that some assignments of nondisjunction will be wrong (Carothers 1987). Second, cytogenetic analysis of Qbanding heteromorphisms is informative in only $50 \%$ of cases. When combined with the nucleolus-organizing region (NOR)silver staining technique, this figure rises to $80 \%$ (Mikkelsen et al. 1980), but this still leaves one-fifth of cases in which the origin of nondisjunction cannot be determined. Third, recombination resulting from crossing-over between the centromere and the short-arm markers could lead to errors in localisation of the nondisjunction event to a specific meiotic division.

The use of restriction fragment length polymorphism (RFLP) markers to analyse nondisjunction overcomes two of these problems. Detection of allelic variation using RFLPs is objective and it is usually clear from the relative dosage of allels which chromosome is present in more than one copy in the DNA of the child. Further, the availability of numerous polymorphic DNA markers from chromosome 21 should allow the origin of the additional chromosome to be determined in most, if not all, cases. There is thus a need for multiple polymorphic chromosome 21 probes and ideally these would be as close to the centromere as possible to minimise errors in ascertainment due to recombination. These markers can also be used to construct a genetic linkage map of the chromosome, and expressed sequences localised to the critical region may be of importance in the study of the pathogenesis of Down syndrome.

We report here the isolation and regional localisation of thirteen single-copy DNA sequences on chromosome 21 and the use of one of these probes, in conjunction with four previously described polymorphic chromosome 21 probes, to analyse nondisjunction in Down syndrome families.

\section{Materials and methods}

\section{Materials}

Restriction enzymes were obtained from Bethesda Research Laboratories. DNA samples were radiolabelled by the random primer method (Feinberg and Vogelstein 1983), using unlabelled dATP, dGTP, and TTP from Sigma, hexadeoxyribonucleotides from Pharmacia, and Klenow enzyme from Northumbria Biologicals; $\left[\alpha-{ }^{32} \mathrm{P}\right]-\mathrm{dCTP}$ was obtained from Amersham, as was Hybond-N nylon membrane. 


\section{Recombinant DNA library/isolation of probes}

The recombinant library used was prepared by flow-sorting from a human diploid fibroblast cell line at the Lawrence Livermore Laboratory (Fuscoe et al. 1986). Chromosome 21 DNA was isolated, digested with the restriction enzyme HindIII, and cloned into the bacteriophage vector Charon $21 \mathrm{~A}$. The average insert size is $4.0 \mathrm{~kb}$, with an estimated $34 \%$ of clones being nonrecombinants (Fuscoe 1987). Screening of the library and isolation and labelling of probes were performed as described by Gillard et al. (1987).

\section{Southern hybridization}

Preparation, digestion, and Southern analysis of DNA samples were performed as described in Gillard et al. (1987). Filters were exposed to X-ray film (Kodak XAR5) at $-70^{\circ} \mathrm{C}$ with intensifying screens (Cronex/Du Pont). Exposure times ranged from $20 \mathrm{~h}$ to 7 days.

\section{Cytogenetic analysis}

Metaphase spreads were prepared from peripheral blood cultures and chromosome heteromorphisms of the parents and trisomic infants were compared using Q-banding (Caspersson et al. 1970). All five cases were examined directly under the microscope by two independent observers.

\section{DNA probes}

Probes pGSE8(D21S15), pGSH8(D21S17) and pGSM21 (D21S13) were obtained from Dr. Gordon Stewart and probe 10.2(D21S25) from Professor Peter Pearson. Details on polymorphisms detected can be found in Human Gene Mapping 9 (1987); mapping information on these probes is given in Table 2.

\section{Cell lines}

The regions of chromosome 21 present in each hybrid cell line are shown in Fig. 1 and 2. THYB133R is a mouse/human hybrid, a derivative of THYB133 (Goodfellow et al. 1980), obtained from Dr.C. Bostock, and contains chromosome 21 as its only detectable human chromosome. A1WBf2 is a Chinese hamster/human hybrid, obtained from Professor P.Pearson, which contains the region $21 q 21$-qter as part of a $12 ; 21$ translocation, originally derived from a patient carrying this rearranged chromosome. Unpublished results of Pearson et al. and our own results with other, well-characterised chromosome 21 DNA probes (e.g. Stewart et al. 1985) confirm that this is the only chromosome 21 material present in this hybrid. AHVI-17 was obtained from Professor D. Cox and contains the pter-q22.1 region of chromosome 21 as part of a $1 ; 21$ translocation chromosome; the reciprocal translocation product and the normal chromosome 21 are not present (Korenberg et al. 1987). BW5147 (Hyman and Stallings 1974) is a mouse cell line, obtained from Dr.P. Goodfellow. TrD2 is a human fibroblast cell line obtained from Dr. N. Carpenter with the chromosome constitution $45 \mathrm{XX},-21+\mathrm{t}(4 ; 21)(\mathrm{p} 16.3, \mathrm{q} 21)$. One part of the reciprocal translocation is absent so this individual is essentially monosomic for the region 21 pter-q21 (Carpenter et al. 1987). All other cell lines used were kindly provided by Professor D. Patterson and are described in Patterson et al. (1985) and Van Keuren et al. (1986a, b), except
ACEM2-90, which is described in Bradley et al. (1986). It should be noted that " $8 \mathrm{q}$-" is a convenient laboratory abbreviation for this hybrid, the correct name being 13b1S816-10-3 (Van Keuren et al. 1986b).

\section{Patients}

In 22 of the Down syndrome families studied, the parents were attending the West of Scotland Regional Genetic Center for genetic counselling following the birth of a child with cytogenetically confirmed trisomy 21. DNA was obtained from peripheral blood samples from each parent and the child. In the other 11 families the trisomy 21 DNA sample was obtained from fetal cells, following prenatal diagnosis and termination of a Down syndrome fetus.

\section{Results}

\section{Isolation of single-copy DNA sequences}

We collected and purified 480 plaques that had failed to hybridize with total human genomic DNA, in the hope that these would contain low- or single-copy human DNA inserts. Of these, 120 were further characterised, and 23 clones containing insert DNA were identified. The inserts were then labelled and hybridized to human genomic DNA samples to identify single-copy sequences. In this way, 13 single-copy human DNA sequences were identified. These were characterised as described below.

\section{Regional localisation of DNA sequences}

Each of the single-copy DNA sequences were hybridized to the panel of somatic cell hybrids outlined in Fig. 1, with the following results. Eight of the probes (JG12/D21S85, JG22/D21S87, JG24/D21S88, JG63/D21S91, JG77/D21S93, JG81/D21S94, JG108/D21S99, JG373/D21S101) hybridized to all of the panel DNAs except lanes 3 and 7 . This allows these sequences to be localised to the region of chromosome 21 absent from hybrid AHVI-17, which is 21q22.1-21qter. The remaining five probes (JG21/D21S86, JG62/D21S90, JG72/D21S92, JG90/ D21S95, JG99/D21S97) hybridized to all of the panel DNAs except mouse DNA (lane 7). These sequences therefore map in the region of overlap between hybrids A1WBf2 (lane 2) and AHVI-17 (lane 3), defined cytogenetically as 21q2121q22.1. Given the high degree of similarity between the hybridization patterns, results are presented in Fig. 1 only for probes JG373/D21S101 and JG72/D21S92, as representative examples of each group. The relative intensities of hybridization signal within each panel showed that despite our efforts, unequal amounts of DNA were present in each track and hence no conclusions on the regional localisation of DNA sequences could be drawn from difference in dosage of hybridization signal.

\section{Increased accuracy of mapping using additional hybrids}

Five of the probes were also mapped using a more extensive panel of hybrids, as illustrated in Fig. 2. An example of the type of hybridization pattern found is shown for probe JG21/ D21S86. Probes JG72/D21S92 and JG90/D21S95 showed an identical pattern of hybridization to this panel as found with JG21, confirming the localisation of all three to $21 \mathrm{q} 21$ - 

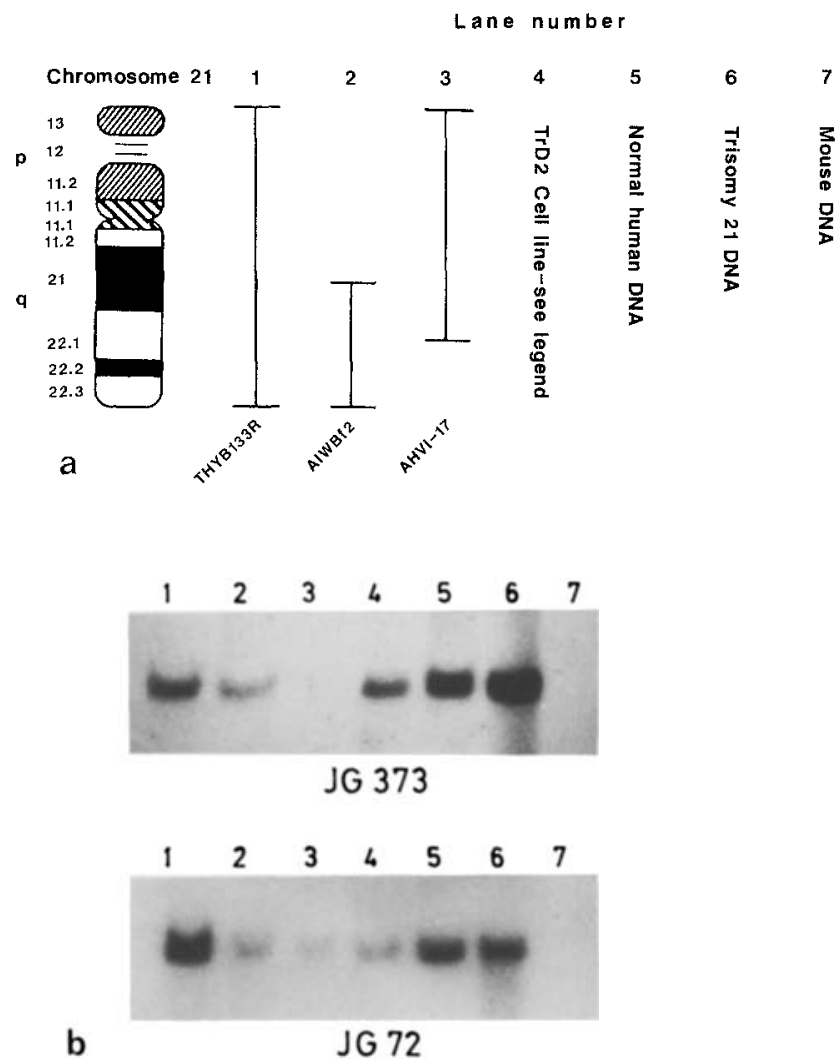

Fig.1. a Diagram of the human chromosome 21 constitution of the seven-member hybrid mapping panel (lanes $1-7$ ). (Cell line TrD2 is essentially monosomic for the region 21pter-21q21). b Autoradiographs showing hybridization of DNA probes JG373/D21S101 and $\mathrm{JG} 72 / \mathrm{D} 21 \mathrm{~S} 92$ to this panel

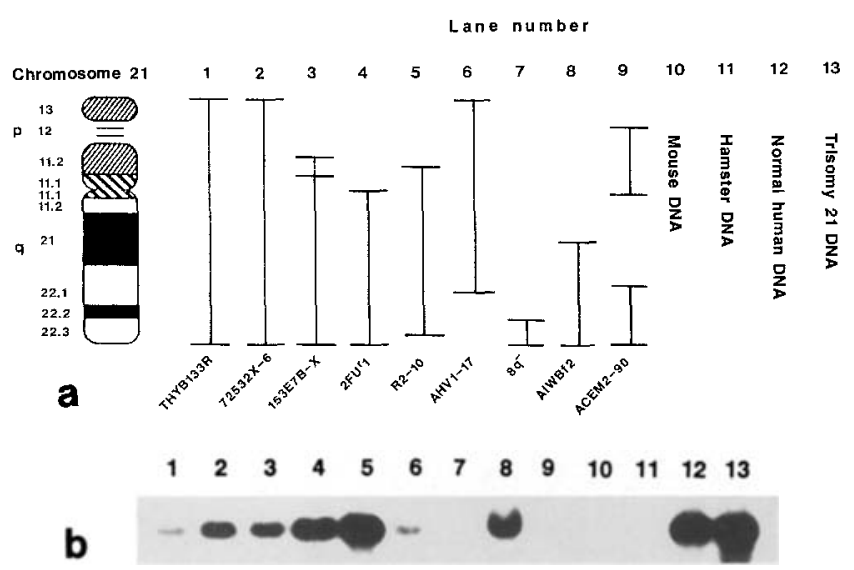

Fig. 2. a Diagram of the human chromosome 21 constitution of the 13member hybrid mapping panel (lanes 1-13). b Autoradiograph showing hybridization of probe JG21/D21S86 to this panel

$21 q 22.1$, and moving the lower limit of this region to a slightly more proximal location, as defined by hybrid ACEM2-90 (lane 9). The only DNA samples to which probe JG77 (D21S93) did not hybridize were those in lanes $6,7,10$, and 11. This allows the accurate localisation of this sequence to the region between the breakpoints of the hybrids AHVI-17 (lane 6) and 8q(lane 7), which is 21q22.1-21q22.2. Probe JG373/D21S101 failed to hybridize with hybrids R2-10 (lane 5) and AHVI-17 (lane 6), and can be localised to a small region in the distal

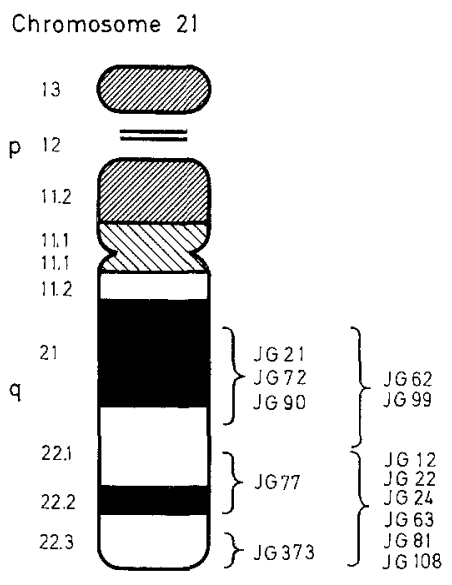

Fig. 3. Diagram showing the regional localisation of the 13 single-copy DNA probes on chromosome 21

Table 1. Details of restriction fragment length polymorphisms (RFLPs) detected during this study

\begin{tabular}{llllllll}
\hline Probe & Enzyme & $\begin{array}{l}\text { Con- } \\
\text { stant } \\
\text { band } \\
(\mathrm{kb})\end{array}$ & $\begin{array}{l}\text { Al- } \\
\text { lele }\end{array}$ & $\begin{array}{l}\text { Length } \\
(\mathrm{kb})\end{array}$ & $\begin{array}{l}\text { Fre- } \\
\text { quency }\end{array}$ & $\begin{array}{l}\text { Indi- } \\
\text { vid- } \\
\text { uals } \\
\text { tested }\end{array}$ \\
\hline HG77 & MspI & 5.0 & 1 & 6.0 & 0.67 & 62 & 0.34 \\
& & & 2 & 3.0 & 0.33 & & \\
JG81 & EcoRV & 7.5 & 1 & 5.0 & 0.88 & 19 & 0.20 \\
& & & 2 & 4.5 & 0.12 & & \\
JG81 & PvuII & 3.5 & 1 & 8.5 & 0.83 & 12 & 0.24 \\
& & & 2 & 8.0 & 0.17 & & \\
JG90 & \multirow{2}{*}{ NdeII } & 1.2 & 1 & 2.2 & 0.70 & 20 & 0.33 \\
& & & 2 & 1.8 & 0.30 & & \\
JG99 & \multirow{2}{*}{ PstI } & - & 1 & 7.0 & 0.16 & 16 & 0.23 \\
& & & 2 & 6.6 & 0.84 & & \\
\hline
\end{tabular}

${ }^{a}$ PIC, Polymorphism information content. See Skolnick and White (1982) for explanation

part of band 21q22.3. The regional localisations for all 13 probes are summarised in Fig. 3.

\section{Screening of probes for RFLPs}

RFLP screening was carried out for eight of the probes (JG62/ D21S90, JG63/D21S91, JG72/D21S92, JG77/D21S93, JG81/ D21S94, JG90/D21S95, JG99/D21S97 and JG108/D21S99), using a total of 12 human genomic DNA samples of different ethnic origin and 20 restriction endonucleases. This revealed a total of five polymorphisms with four of the probes, details of which are given in Table 1.

\section{Analysis of nondisjunction in Down syndrome families}

Parental origin. Of the 33 families examined using chromosome-21-linked RFLP markers, the parental origin of the additional chromosome 21 was determined in 12 cases ( $36 \%)$. In 9 of these $(75 \%)$, the extra chromosome was of maternal origin, while in the other $3(25 \%)$ it was derived from the father.

Five families were also analysed cytogenetically using Qbanding heteromorphisms, which proved informative in three cases. In each of these families the results obtained with the DNA markers were confirmed. Details of the RFLP and cytogenetic marker results are given in Table 2, which also gives information on the parental ages. 
Table 2. Summary of cytogenetic and restriction fragment length polymorphism (RFLP) analysis of informative Down syndrome (DS) families based on Table 3 of Hassold et al. (1987). F, Father; C, child; M, mother

\begin{tabular}{|c|c|c|c|c|c|c|c|c|c|c|}
\hline \multicolumn{2}{|c|}{ Family } & $\begin{array}{l}\text { Cyto- } \\
\text { genetic }^{a} \\
\text { analysis }\end{array}$ & $\begin{array}{l}\text { Locus: } \\
\text { Probe: } \\
\text { Enzyme: } \\
\text { Location: }\end{array}$ & $\begin{array}{l}\text { D21S13 } \\
\text { pGSM21 } \\
\text { TaqI } \\
\text { q11.1 }\end{array}$ & $\begin{array}{l}\mathrm{D} 21 \mathrm{~S} 93 \\
\mathrm{JG} 77 \\
M s p \mathrm{I} \\
(\mathrm{q} 22.1-\mathrm{q} 22.2)\end{array}$ & $\begin{array}{l}\mathrm{D} 21 \mathrm{~S} 25 \\
10.2 \\
\text { HindIII } \\
(\mathrm{q} 22.1-\mathrm{q} 22.2)\end{array}$ & $\begin{array}{l}\mathrm{D} 21 \mathrm{~S} 17 \\
\mathrm{H} 8 \\
B g l \mathrm{II} \\
\mathrm{q} 22.3\end{array}$ & $\begin{array}{l}\text { D21S15 } \\
\text { E8 } \\
\text { MspI } \\
\text { q22.3 }\end{array}$ & $\begin{array}{l}\text { Age at } \\
\text { birth } \\
\text { of DS } \\
\text { child }\end{array}$ & $\begin{array}{l}\text { Meiotic } \\
\text { stage } \\
\text { of ñon- } \\
\text { disjunction }\end{array}$ \\
\hline F & 1 & - & & $11^{\mathrm{b}}$ & 11 & 11 & 12 & - & 41 & \\
\hline $\mathrm{C}$ & 2 & - & & $122^{\mathrm{c}}$ & 112 & $122^{\mathrm{c}}$ & 111 & - & & Maternal II \\
\hline M & 3 & - & & 12 & 12 & 22 & 11 & - & 42 & \\
\hline $\mathrm{F}$ & 4 & $a b$ & & 12 & 12 & 11 & 11 & 11 & 42 & \\
\hline $\mathrm{C}$ & 5 & aaa & & 112 & 122 & $122^{\mathrm{c}}$ & 111 & $122^{\circ}$ & & Maternal II \\
\hline $\mathbf{M}$ & 6 & aa & & 12 & 12 & 22 & 11 & 12 & 37 & \\
\hline F & 7 & - & & 22 & 12 & 22 & 11 & 12 & 29 & \\
\hline $\mathrm{C}$ & 8 & - & & 222 & 122 & 222 & $122^{c}$ & 122 & & Paternal \\
\hline M & 9 & - & & 12 & 12 & 22 & 22 & 12 & 27 & \\
\hline $\mathrm{F}$ & 13 & $a b$ & & - & 11 & 22 & 22 & 12 & 32 & \\
\hline $\mathrm{C}$ & 14 & $a a b$ & & - & 112 & 222 & $112^{\mathrm{c}}$ & 112 & & Maternal \\
\hline M & 15 & ac & & - & 12 & 22 & 11 & 11 & 30 & \\
\hline F & 16 & $a b$ & & 22 & 11 & - & 12 & - & 43 & \\
\hline $\mathrm{C}$ & 17 & $\mathrm{bcd}^{\mathrm{c}}$ & & $112^{c}$ & 111 & - & 112 & - & & Maternal I \\
\hline $\mathrm{M}$ & 18 & $\mathrm{~cd}$ & & 11 & 11 & - & 12 & - & 33 & \\
\hline $\mathrm{F}$ & 25 & $a b$ & & 11 & 11 & - & 11 & - & 31 & \\
\hline C & 26 & $\mathrm{acd}^{\mathrm{c}}$ & & $112^{\mathrm{d}}$ & - & $122^{\mathrm{c}}$ & - & & & Maternal I \\
\hline $\mathrm{M}$ & 27 & $\mathrm{~cd}$ & & 12 & 12 & - & 22 & - & 34 & \\
\hline $\mathrm{F}$ & 28 & $a b$ & & 12 & 12 & - & 12 & 12 & 34 & \\
\hline $\mathrm{C}$ & 29 & $b c d^{c}$ & & 112 & 112 & - & 122 & $112^{\mathrm{c}}$ & & Maternal I \\
\hline M & 30 & $\mathrm{~cd}$ & & 11 & 11 & - & 12 & 11 & 30 & \\
\hline $\mathbf{F}$ & 31 & - & & 12 & 22 & 22 & 12 & - & 27 & \\
\hline $\mathrm{C}$ & 32 & - & & $111^{\mathrm{d}}$ & $122^{\mathrm{c}}$ & $122^{c}$ & 122 & - & & Paternal II \\
\hline M & 33 & - & & 11 & 11 & 11 & 12 & - & 26 & \\
\hline $\mathrm{F}$ & 37 & - & & - & 11 & 13 & 11 & - & 30 & \\
\hline C & 38 & - & & - & $122^{c}$ & $122^{\mathrm{c}}$ & $112^{\mathrm{d}}$ & - & & Maternal I \\
\hline M & 39 & - & & - & 22 & 22 & 12 & - & 33 & \\
\hline $\mathrm{F}$ & 90 & - & & - & - & 12 & - & - & 44 & \\
\hline C & 91 & - & & - & - & $112^{c}$ & - & - & & Paternal II \\
\hline M & 92 & - & & - & - & 22 & - & - & 42 & \\
\hline$F$ & 135 & - & & - & - & 22 & - & - & 37 & \\
\hline $\mathrm{C}$ & 136 & - & & - & - & $112^{c}$ & - & - & & Maternal II \\
\hline M & 137 & - & & - & - & 12 & - & - & 37 & \\
\hline $\mathrm{F}$ & 153 & - & & - & - & 22 & - & - & 43 & \\
\hline $\mathrm{C}$ & 154 & - & & - & - & $112^{c}$ & - & - & & Maternal \\
\hline M & 155 & - & & - & - & 11 & - & - & 41 & \\
\hline
\end{tabular}

${ }^{a}$ Cytogenetic markers were arbitrarily assigned as $\mathrm{a}, \mathrm{b}, \mathrm{c}$, or $\mathrm{d}$

${ }^{\mathrm{b}} \mathrm{RFL} P$ alleles are denoted by 1,2 , and 3

'Parental origin can be determined

${ }^{\mathrm{d}}$ The meiotic stage of non-disjunction can be inferred

${ }^{\mathrm{e}}$ In the last three families the parental ages given are those at the time of termination of a trisomy 21 fetus

Meiotic stage of nondisjunction. The meiotic stage of nondisjunction was determined in 9 of the 12 informative families (Table 2). In five of these families, the meiotic stage of nondisjunction is defined by cytogenetic (Q-banding) heteromorphisms or by the RFLP marker D21S13/TaqI, both of which map close to the centromere. The probability of crossing-over between the centromere and these markers is greatly reduced in these cases, and the results are considered reliable. This is especially true in families $16-17-18$ and $25-26-27$, since in both cases the Q-banding and D21S13/TaqI results, which flank the centromere, are in agreement. In the other four families $(4-5-6,37-38-39,90-91-92$, and 135-136-137), 


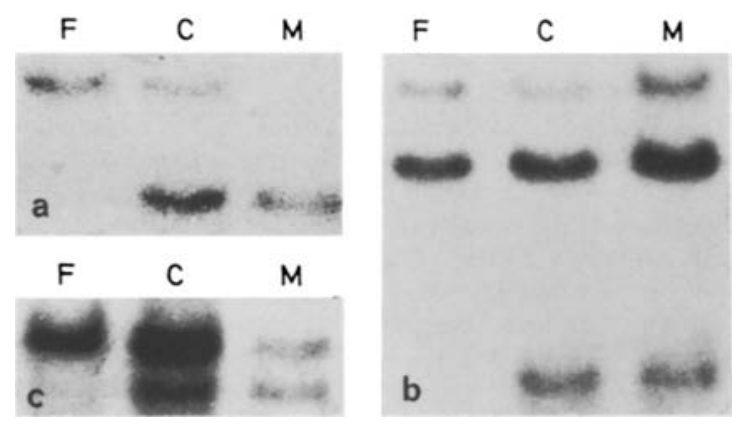

Fig. 4a-c. Restriction fragment length polymorphism (RFLP) results for family 25-26-27: a H8/BgIII; b JG77/MspI; c pGSM21/TaqI. $F$ Father, $C$ child, $M$ mother

however, this information is provided by RFLP markers on the distal long arm of chromosome 21. Although recombination would not affect the determination of parental origin, it could lead to errors in assignment of nondisjunction to a specific meiotic division, and these four results must be considered provisional until confirmed or corrected using appropriate pericentromeric markers.

Demonstration of recombination between nondisjoined chromosomes 21 . Analysis of family 25-26-27 with the H8/BglII polymorphism shows that the additional chromosome 21 is of maternal origin (Fig. 4a). The results obtained using JG77/ MspI confirm maternal origin of nondisjunction and localise the error to the second meiotic division (Fig. 4b). The hybridization pattern obtained with the D21S13/TaqI marker provides no direct information regarding the parental origin of the extra chromosome, but given the prior knowledge that maternal nondisjunction has occurred in this family, the pattern and relative band intensities with this marker show nondisjunction to have taken place at the first maternal meiotic division (Fig. 4c). Q-banding studies were also informative in this family and localised nondisjunction to the first maternal meiotic division. This apparent contradiction between the JG77 and pGSM21/Q-banding results demonstrates that recombination must have occurred between these two sets of markers prior to nondisjunction at the first maternal meiotic division in this family.

\section{Discussion}

Screening of this flow-sorted library has thus provided 13 single-copy DNA sequences, which map to five distinct regions on the long arm of chromosome 21 . This brings the total number of 21-specific arbitrary DNA sequences to 112 (Pearson et al. 1987). In addition, 12 cloned genes have been assigned to this chromosome and of these genes and arbitrary DNA sequences, 38 detect one or more RFLPs (Pearson et al. 1987). These polymorphic DNA sequences have important applications: analysis of the origin of nondisjunction, detection of recombination between nondisjoined chromosomes, and the construction of a genetic linkage map of chromosome 21 , which in turn can be used to assign genetic traits to this chromosome.

Of the 13 single-copy DNA probes described here, 5 were tested by Northern blot analysis (JG72/D21S92, JG77/D21S93, JG81/D21S94, JG90/D21S95, and JG108/D21S99). As described by Stefani et al. (1988), probes JG77 and JG90 were
Table 3. Comparison of cytogenetic and restriction fragment length polymorphism (RFLP) studies of nondisjunction in Down syndrome families

\begin{tabular}{llrr}
\hline & Reference & $\begin{array}{l}\text { Parental origin } \\
\text { of additional } \\
\text { chromosome 21 }\end{array}$ \\
\cline { 3 - 4 } & & $\begin{array}{c}\text { Mater- } \\
\text { nal }\end{array}$ & $\begin{array}{l}\text { Pater- } \\
\text { nal }\end{array}$ \\
\hline Studies using & Mikkelsen et al. (1980) & 61 & 12 \\
cytogenetic & Magenis and Chamberlin (1981) & 151 & 46 \\
markers & Jongbloet et al. (1981) & 51 & 13 \\
& Hatcher et al. (1982) & 24 & 3 \\
& Ayme et al. (1986) & 416 & 98 \\
& Total & 703 & 172 \\
Studies using & Percentage & 80 & 20 \\
RFLP & Davies et al. (1984) & 1 & 0 \\
markers & Antonarakis et al. (1986) & 22 & 3 \\
& Stewart et al. (1988) & 4 & 1 \\
& Rudd et al. (1988) & 7 & 2 \\
& Present study & 9 & 3 \\
& Total & 43 & 9 \\
& Percentage & 83 & 17 \\
\hline
\end{tabular}

shown to be expressed at an increased level in Down syndrome as compared to normal brain tissue. Given their regional localisation on chromosome 21 (see Fig. 3), the possibility exists that these sequences may represent parts of genes on chromosome 21 important in the pathogenesis of Down syndrome and Alzheimer's disease (St.George-Hyslop et al. 1987), respectively. Further investigation of these two sequences is an obvious next step.

During the course of the current project a total of 33 Down syndrome families were examined using five chromosome-21specific RFLP markers, and although it was not possible to test every family with each probe, the parental origin of the additional chromosome was determined in 12 families (36\%). The majority of cases showed maternal nondisjunction ( 9 families, $75 \%$ ) as opposed to paternal nondisjunction ( 3 families, $25 \%$ ). Due to the small sample size and the lack of an appropriate control population, we did not draw any conclusions regarding the relationship between parental age and nondisjunction based on these results. It is interesting, nevertheless, to note that in two of the cases showing paternal nondisjunction (7-89 and 31-32-33), the age of the mother was significantly lower than the mean maternal age in the other informative families (Table 2). In family 90-91-92, which also showed paternal nondisjunction, the trisomy 21 DNA sample was obtained from a terminated trisomy 21 fetus. It could be argued, therefore, that this family is not representative of the total population at risk for nondisjunction, as the mother was selected for prenatal diagnosis because of her advanced age at the time of conception.

Four other groups have published data on RFLP analysis of nondisjunction in trisomy 21: details of these studies and of selected large cytogenetic studies are given in Table 3. Although the sample size in the RFLP studies performed so far is relatively small, the proportions of maternal and paternal errors agree almost exactly with those obtained in the numerous studies of cytogenetic hetermorphisms. Both show that $80 \%$ of nondisjunction errors occurred in the mother, while the remaining $20 \%$ took place during paternal meioses. 
Crossing-over between two nondisjoined chromosomes can be detected only when the parent of origin is heterozygous for two or more markers. An example of this type of pattern is presented here for family 25-26-27 (Fig. 4, Table 2), in which recombination must have occurred between the markers D21S13/TaqI and JG77/MspI, followed by nondisjunction at maternal meiosis $\mathrm{I}$. These results demonstrate that recombination between the centromere and RFLP markers on the long arm of chromosome 21 can complicate the assignment of nondisjunction to a specific meiotic division using polymorphic DNA probes. The combination of cytogenetic and pericentromeric RFLP markers with polymorphic markers on the long arm of the chromosome should eliminate the confounding effects of such recombination. Similar crossover events are described in two of the five Down syndrome families studied by Stewart et al. (1988) and in four of the seven trisomy 13 families described by Hassold et al. (1987).

In the recent paper by Antonarakis et al. (1986), the authors estimated the levels of recombination on chromosomes 21 involved in normal meioses with those undergoing nondisjunction in 34 Down syndrome individuals, their parents, and normal siblings. They reported statistically significant reductions in the map distances associated with trisomy 21 and stated that recombination involving the two nondisjoined chromosomes was rarely detected. From these results it was suggested that recombination is reduced between those chromosomes 21 that undergo nondisjunction and that defective pairing may consequently be responsible for a large proportion of cases of trisomy 21 . The results obtained in the present study and by other workers (Hassold et al. 1987; Stewart et al. 1988), demonstrating recombination between nondisjoined chromosomes in a significant proportion of cases, suggest that pairing failure due to reduced recombination is not the only cause of autosomal trisomy. To fully investigate the possible relevance of aberrant recombination levels on nondisjunction, a large sample should be studied using both cytogenetic and pericentromeric RFLP markers in conjunction with RFLP markers spanning the whole length of the long arm of chromosome 21.

Of the five Down syndrome families analysed using Qbanding heteromorphism in this study, three proved to be informative and in each case the cytogenetic and RFLP results agreed (Table 2). In two families (16-17-18 and 28-29-30) cytogenetic analysis provided information on the meiotic stage of nondisjunction that was not available with the RFLP markers used here.

It is obvious that the use of a sufficiently large number of RFLP markers should allow the origin of the additional chromosome to be determined in every Down syndrome family. The studies mentioned above by Hassold et al. (1987) and Stewart et al. (1988) suggest that a different strategy might be just as productive. Both groups used a small proportion of the available polymorphic DNA markers in conjunction with cytogenetic techniques to analyse nondisjunction and were able to determine the parental origin of the extra chromosome in all cases tested.

Acknowledgements. This work was performed during the Ph.D. project of J.G., which was funded from October 1983 to September 1986 by the Medical Research Council. Some of the RFLP results shown here were presented in Stewart et al. (1985). Thanks are due to Mrs. N. Morrison for the maintenance and culture of somatic cell hybrid cell lines and to Mr.Alan Ramsay who discovered the JG90/ NdeII polymorphism. The Scottish Down Syndrome Association helped to gather families willing to participate in this project.

\section{References}

Antonarakis SE, Chakravati A, Warren AC, Slaugenhaupt SA, Wong C, Halloran SL, Metaxotou C (1986) Reduced recombination rate on chromosomes 21 that have undergone nondisjunction. Cold Spring Harbor Symp Quant Biol 51:158-190

Ayme S, Baccicheti C, Bricarelli FD, Dallapiccola B, Lungarotti D, Mikkelsen M, Nevin N (1986) Factors involved in chromosomal nondisjunction: a European collaborative study, supported by the EEC. 7th International Congress of Human Genetics, Berlin 1986, part I: C IV.19 (abstr)

Bradley CM, Patterson D, Robinson A (1986) Somatic cell genetic studies on the family with Down syndrome due to an unusual translocation (21q22-21qter). Trisomy $211: 41-52$

Carothers A (1987) Down syndrome and maternal age: the effect of erroneous assignment of parental origin. Am J Hum Genet $40: 147-150$

Carpenter NJ, Mayes JS, Say B, Wilson DP (1987) Partial deletion 21: case report with biochemical studies and review. J Med Genet $24: 706-709$

Caspersson T, Zech L, Johansson C, Modest EJ (1970) Identification of human chromosomes by DNA-binding fluorescent agents. Chromosoma 30:215-227

Davies KE, Harper K, Bonthron D, Krumlauf R, Polkey A, Pembrey ME, Wiliamson R (1984) Use of a chromosome 21 cloned DNA probe for the analysis of nondisjunction in Down syndrome. Hum Genet 66:54-56

Feinberg AP, Vogelstein B (1983) A technique for radiolabelling DNA restriction endonuclease fragments to high specific activity. Anal Biochem 132:6-13 (Addendum [1984] Anal Biochem 137: 266-267)

Fuscoe JC (1987) Human chromosome specific DNA libraries: use of an oligodeoxynucleotide probe to detect non-recombinants. Gene $52: 291-296$

Fuscoe JC, Clark LM, Van Dilla MA (1986) Construction of fifteen human chromosome-specific DNA libraries from flow-purified chromosomes. Cytogenet Cell Genet 43:79-86

Gillard EF, Affara NA, Yates JRW, Goudie DR, Lambert J, Aitken DA, Ferguson-Smith MA (1987) Deletion of a DNA sequence in eight of nine families with X-linked ichthyosis (steroid sulphatase deficiency). Nucleic Acids Res 15:3977-3985

Goodfellow P, Banting G, Levy R, Povey S, McMichael P (1980) A human $\mathrm{X}$-linked antigen linked by a monoclonal antibody. Somatic Cell Mol Genet 6:777-787

Hassold T, Jacobs PA, Leppert M, Sheldon M (1987) Cytogenetic and molecular studies of trisomy 13. J Med Genet 24:725-732

Hatcher NH, Healy NP, Hook EB, Willey AM (1982) Unexpected high proportion of first meiotic nondisjunction in trisomy 21. Am J Hum Genet 34:127A

Human Gene Mapping 9 (1987) 9th International Workshop on Human Gene Mapping. Cytogenet Cell Genet 46:1-762

Hyman RL, Stallings V (1974) Complementation patterns of Thy-1 variants and evidence that antigen loss variants "pre-exist" in the parental population. J Natl Cancer Inst 52:429-436

Jongbloet PH, Frants RR, Hamers AJ (1981) Parental alpha-1-antitrypsin (PI) types and meiotic nondisjunction in the etiology of Down syndrome. Clin Genet 20:304-309

Juberg RC, Mowrey PN (1983) Origin of nondisjunction in trisomy 21 syndrome: all studies compiled, parental age analysis, and international comparisons. Am J Med Genet 16:111-116

Korenberg JR, Croyle ML, Cox DR (1987) Isolation and regional mapping of DNA sequences unique to human chromosome 21. Am J Hum Genet 41:963-978

Magenis RE, Chamberlin J (1981) Parental origin of nondisjunction in trisomy 21. In: Cruz FF de la, Gerald PS (eds) Trisomy 21 (Down syndrome): research perspectives. University Park Press, Baltimore, pp 77-93

Mikkelsen M, Hanne P, Jorgen G, Aksel L (1980) Nondisjunction in trisomy 21: study of chromosomal heteromorphisms in 110 families. Ann Hum Genet 44:17-28

Patterson D, Van Keuren ML, Drabkin HA, Watkins PC, Gusella JF, Scoggin C (1985) Molecular analysis of chromosome 21 using somatic cell hybrids. Ann NY Acad Sci 450:109-120 
Pearson PL, Kidd KK, Willard HF (1987) Report of the committee on human gene mapping by recombinant DNA techniques. (9th International Workshop on Human Gene Mapping) Cytogenet Cell Genet 46:390-566

Rudd NL, Dimnik LS, Greentree C, Mendes-Crabb K, Hoar DI (1988) The use of DNA probes to establish parental origin in Down syndrome. Hum Genet 78: 175-178

St George-Hyslop PH, Tanzi RE, Polinsky RJ, Haines JL, Nee L, Watkins PC, Myers RH, Feldman RG, Pollen D, Drachman D, Growdon G, Bruni A, Foncin J-F, Salmon D, Frommelt P, Amaducci L, Sorbi S, Piacentini S, Stewart GD, Hobbs WJ, Conneally PM, Gusella JF (1987) The genetic defect causing familial Alzheimer's disease maps on chromosome 21. Science 235:885890

Stefani L, Galt J, Palmer A, Affara N, Ferguson-Smith MA, Nevin NC (1988) Expression of chromosome 21-specific sequences in normal and Down's syndrome tissues. Nucleic Acids Res 15: 2885-2896

Stewart GD, Harris P, Galt J, Ferguson-Smith MA (1985) Cloned DNA probes regionally mapped to human chromosome 21 and their use in determining the origin of nondisjunction. Nucleic Acids Res 13:4125-4132
Stewart GD, Hassold TJ, Berg A, Watkins PC, Tanzi RE, Kurnit DM (1988) Trisomy 21 (Down syndrome): studying nondisjunction and meiotic recombination using cytogenetic and molecular polymorphisms that span chromosome 21. Am J Hum Genet 42:344346

Summitt RL (1981) Specific segments that cause the phenotype of Down syndrome. In: Cruz FF de la, Gerald PS (eds) Trisomy 21 (Down syndrome): research perspectives. University Park Press, Baltimore, pp 225-235

Van Keuren ML, Watkins PC, Drabkin HA, Jabs EW, Gusella JF, Patterson D (1986a) Regional localisation of DNA sequences on chromosome 21 using somatic cell hybrids. Am J Hum Genet 38:793-804

Van Keuren ML, Drabkin HA, Hart I, Harker D, Patterson D, Vora S (1986b) Regional assignment of liver-type 6-phosphofructokinase to chromosome $21 \mathrm{q} 22.3$ by using somatic cell hybrids and a monoclonal anti-L antibody. Hum Genet $74: 34-40$

Received May 20, 1988 / Revised August 2, 1988 